\title{
Language Education in Russian Universities: Advantages, Vulnerabilities and Risks of Online Teaching
}

\author{
Anton Lebedev ${ }^{1}$, Natalya Shamina ${ }^{1}$, Iuliia Pinkovetskaia ${ }^{2, *}$ \\ ${ }^{1}$ Department of the English Language for Professional Communication, Foreign Languages Faculty, N. P. Ogarev's Mordovia State \\ University, Saransk, 430005, Russia \\ ${ }^{2}$ Department of the Economic Analysis and State Management, Institute of Economics and Business, Ulyanovsk State University, \\ Ulyanovsk, 432000, Russia
}

Received October 14, 2020; Revised November 27, 2020; Accepted December 20, 2020

\section{Cite This Paper in the following Citation Styles}

(a): [1] Anton Lebedev, Natalya Shamina, Iuliia Pinkovetskaia, "Language Education in Russian Universities: Advantages, Vulnerabilities and Risks of Online Teaching," Universal Journal of Educational Research, Vol. 8, No. 12B, pp. 8159-8168, 2020. DOI: 10.13189/ujer.2020.082619.

(b): Anton Lebedev, Natalya Shamina, Iuliia Pinkovetskaia (2020). Language Education in Russian Universities: Advantages, Vulnerabilities and Risks of Online Teaching. Universal Journal of Educational Research, 8(12B), 8159-8168. DOI: 10.13189/ujer.2020.082619.

Copyright $\bigcirc 2020$ by authors, all rights reserved. Authors agree that this article remains permanently open access under the terms of the Creative Commons Attribution License 4.0 International License

\begin{abstract}
At the moment, education systems around the world are taking measures to organize education in the context of the coronavirus (COVID-19) pandemic. In most countries many students are transferred to distance learning. Online education provides a wide range of opportunities and prospects for changing and improving educational systems, for which a critical situation creates forced conditions. The article analyzes the problems associated with the use of online learning. The methodological and theoretical foundation of the work is provided by a systematic approach, the concept of social conditioning of language education, the notion of continuous vocational training. When using online courses as a means of teaching a foreign language, we offer both special programs for teaching a language and checking knowledge of vocabulary and grammar, as well as modern authentic materials for teaching reading and listening. In the process of teaching a foreign language, students perform various types of work: they translate foreign texts and articles, make reports, practice creative project activities and prepare presentations. The priority goal of the article is to identify the advantages, vulnerabilities and risks of online learning. It is shown that mass character, the use of modern and interactive technologies belong to the strengths of online learning. However, the absence of direct contact between the teacher and the student does not allow
\end{abstract}

implementing the competence approach in full measure.

Keywords Online Learning, Language Teaching, Multimedia and Communication Technologies, Anti-COVID Measures, Distant Education, English for Specific Purposes

\section{Introduction}

Online learning (or so-called "distant education") has become an integral and essential part of the educational standards both in Russia and abroad even prior to the COVID pandemic. The factors contributing to the online learning development include shortage of time, increasingly faster life pace, busy work schedules, spread of broadband Internet connectivity and facilities, shift from desktop computers to the mobile devices (on-the-move learning), popularity of "edutainment" (i.e. integration of entertainment and gaming elements into the learning process), cutting of the travel costs, information accessibility etc. While being questioned and debated as a principal education core, online learning is widely embraced as (at least) a supplementary and additional tool that is to be inherent to any higher educational 
organization. According to [3]: "The growth of international cooperation, trade, tourism and emigration arouses the interest of both linguists and teaching experts in the theory and practice of the e-learning and mobile teaching technologies".

Lockdown safety, pandemic conditions and healthcare regulations have recently added a completely new dimension to online learning. Now it is temporarily being considered as a principal tool of education due to pandemic restrictions. Although the limitations vary from one Russian region / territory to another, online courses are partially or fully implemented almost in every higher educational organization, including N.P. Ogarev's Mordovia State University (Saransk) and Ulyanovsk State University, the restrictions and anti-Covid healthcare measures include: wearing masks and protective medical gloves, more frequent cleaning, sanitization and ventilation in school buildings, non-contact temperature tests, social distancing (involving seating in staggered order in the classrooms), rearranging the buildings' entrance and exit patterns (i.e. personnel and students use different doors to access the facilities to prevent mass gatherings), further digitizing of the workflow, alternation of online / offline schedules, restrictions for senior personnel (e.g. "online-only mode" for them) etc. Meanwhile the above-mentioned measures are implemented only in the regions with statistically and relatively low pandemic cases and deaths. In the foreseeable future, the seasonal growth (or the so-called "second wave") might demand a complete lockdown or further restrictions.

The emerging anti-pandemic measures and digitization of the education courses have reshaped and rearranged the learning process, as well as professional thinking and perception. Teaching staff and faculty were forced to quickly acquire the new skills (or improve the existing ones) to master the online learning software, deal with technical issues, introduce new teaching techniques, organizing classes in a completely novel environment. The new and unexpected realia challenged education experts to technical specialists to improve the digital environment and online facilities to control both education process and academic work. This required the update and further development of the university websites, personal online profiles, online attendance and grades, digital workflow connecting them to the existing messaging, audio / video conference software (e.g. Skype, Zoom, Viber, WhatsApp) and social media.

The overall situation raised multiple issues. First, it led to the re-evaluation of the online resources and forced the teaching staff to make them a key element of their work, at least temporarily. Second, it also highlighted a growing need for an instructor's individual approach to the broad diversity of students' needs and demands. Third, it "rekindled" a debate on the topic of traditional versus contemporary teaching methods (i.e. can online courses substitute the offline classes?). Fourth, it limited the capacity for offline activities - both curricular (e.g. conducting experiments in natural sciences' disciplines, teaching practice, medical internship etc.) and extracurricular (sports, drama, academic conferences, international exchange programs).

Thus, while having a non-negotiable advantage in education, the online learning process is also viewed as a source of potential risks and vulnerabilities. Consequently, it demands constant discussion and improvement to meet personal, educational and professional requirements. These issues are of special importance, especially in the sphere of foreign language learning. There exist multiple ways to use digital technologies and Internet resources in foreign language learning, including the implementation of existing applications and materials, as well as joint resources created by teachers and students. N.S. Kirgintseva and S.A. Nechaev [14] argue that "the use of various types of multimedia in teaching a foreign language facilitates the cognitive activity within students, forms a culture of creative operational thinking and the ability to navigate the rapidly changing information flows of modern society". This article concentrates on the use of the online and multimedia means within the framework of information and communication technologies in teaching foreign languages in higher education (based on the example of Russian higher institutions).

\section{Literature Review}

The problem of the digitization of education and e-learning is in focus of various researchers and scholars. They make a comprehensive contribution into the study area by providing their national teaching and academic expertise and experience. For instance, R. Trinder [34] studies informal aspects of e-learning using contemporary methods and argues that "online informal learning of English deserves more attention". The researcher presents an empirical study by surveying Austrian university students', as well as their practices and preferences related to new media methodologies. T.M. Roose and G.E. Newell [26] in the work "Exploring Online Discussions through an Academic Literacies Approach" study "how international students bring their cultural knowledge and experiences into relationship with other writers' ideas" using as an example an extract from an online discussion group, including the assignments, student responses, and comments within a university ESL composition course. The work [12] deal with the digital multimodal composing (DMC) as an instructional activity, discussing its implication, advantages and vulnerabilities.

In the work [25] the scholar considers the existing and possible threats and advances of online education, teaching and academic work as viewed from the perspective of the Chinese colleagues. The study [35] 
analyzes "the goal orientations, implementation intentions, and self-regulated learning behavior in relation to mobile-assisted language learning", showing that the implementation of these techniques is "largely conditioned upon learners' awareness of integrativeness and a sense of mastery in light of their reasons for or goals of learning English". H. Tawil [32] poses a question of the effectiveness of the current developments in the area of language learning and teaching, the research concentrates on the role of educational technology and digital communications in acquisition of new or second foreign languages. The digital innovations and their influence on classroom instruction are studied in the paper [19] based on the survey carried out in Jouf University, Saudi Arabia. C.A. Chapelle [4] investigates into the distribution of computer-assisted language learning (CALL), its integration into the existing language materials and curricula and distinguishing between CALL tools and other language resources. The research titled "Electronic Evaluation: Facts, Challenges and Expectations" [11] from Hassiba Benbouali University of Chlef, Algeria shares the University's and overall national experience in electronic and digital evaluation.

The series of works [13] research the adoption of mobile multimedia and Internet technologies based on the opinions of intermediate female EFL students (15-20 years old) at English Language institutions located in Kerman, Iran. The study of students' attitude to e-learning paradigm in Delta University, Egypt deals with the survey conducted among 100 freshman students, asking them the questions: "1. Does using e-learning software program influence students' attitude towards learning English as a foreign language positively? 2. What are the advantages of e-learning in improving English language skills among freshmen students?". Post-graduate learners in Pakistan and their attitudes to changing of educational realia under the circumstances of anti-Covid measures are surveyed in the study [27]. The conclusion is made that among 100 students of KFUEIT, RYK University and the participation that is found "inspiring" and "positive" within the framework of this field of study.

The introduction and use of the e-learning and distant technologies is studied [9], while the autonomous and informal learning is imaginatively compared to "Riding the Digital Wilds", i.e. the author argues that "the trend has accelerated, with new opportunities for autonomous language learning through mobile devices and the ever increasing availability and use of streaming video and other authentic materials in the target language". H. Chiang [5] from Central Taiwan University of Science and Technology investigates into teacher-led and online text-to-speech dictation for students' vocabulary performance and makes a conclusion that there exists a significant difference between TTS and TLD impacts on the participants' vocabulary mastery.

In the paper "Practice of College English Teaching
Reform Based on Online Open Course" [16] introduces and discusses the construction and application of college English online open course in a vocational college in China based on the experience of Yiwu Industrial \& Commercial College. Z. Bárkányi and S. Melchor-Couto [2] from The Open University, Milton Keynes and University of Roehampton, London, United Kingdom study learners` reaction to speaking skills mastery within the massive open online language course and their "feeling of intimidation" and "anxiety" obtained by comments from the discussion forums.

Currently, research in the field of Internet, digital and online tools in higher education is conducted in the studies of Russian authors [3, 6, 8, 15, 20, 23, 24, 30, 31, 33]. While pedagogical practice leads to deliberations concerning the use of specific methodological tools and their implementation in the so-called "education praxis", scholars conclude that these methodologies are to become an essential component of modern pedagogical discourse. The scholars put forward a thesis of integrating online and e-learning ("distant education") into the regular curricula without violating and diminishing the role of an instructor as a mentor and guide.

\section{Materials and Methods}

The methodological and theoretical foundation of the work is provided by a systematic approach, the concept of social conditioning of language education, the notion of continuous professional training (stipulated by the Russian Federal Educational Standards) and the government regulations of reforming higher education.

Internet technologies in language teaching involve the combination of text, sound, animation, video and graphic images in a computer system using educational multimedia software, a projector and a web camera to ensure individual approach to training, the efficiency of mastering the skills and enhancement of the person's motivation. These teaching aids in foreign language classes provide an opportunity to carry out real communication with native speakers, access to information in centralized information systems, cognitive development and motivation for language learning. For instance, the online learning for Mordovia State University is carried out with the help of the online system (integrated into the University`s website) and supplementary means (messagers and social media). Methodically, the open online course provider https://www.coursera.org/ is used to aid teaching and learning of the foreign language disciplines.

\section{Results}

Nowadays online courses are inherent to the educational process in general. The rapid growth and 
increase in the number of mass online courses are currently attracting attention from educational institutions and education experts. The development of the language education is characterized by the implementation of information and communication technologies in solving the problem of modernizing the education system. Information and communication tools, as well as multimedia and Internet technologies, contribute to the personal development of students and the individual approach in the educational process of higher education. According to [31], "modern ICTs provide active and creative mastery of the studied subject, which allows students to learn the given material at a novel and qualitatively higher level".

N.G. Mathew [19] et al. argue that "the impact of technological innovations on teaching methodologies has always been a subject of debate due to its attempts to substitute face-to-face teaching-learning contexts with a virtual environment". A skilled lecturer is surely able to efficiently influence students in the classroom. However, attention and motivation management can also be carried out through indirect contact, while training via an online course. To accomplish this, there is an increasing demand in the appropriate tools: the visual design of materials, notifications and support of the courses, the logics in organizing of the curriculum and tasks system, etc. Online training facilitates producing a course that will gain popularity with students. Moreover, if the implementation of online training does not take into account the specifics of the discipline and the direction of specific students' training, even an excellent course may lead to negative results. Instructors' qualifications and proper methodological organization are essential not only for creating a course, but also for its application in learning and teaching praxis.

One of the principal teaching tasks - creating the environment for successful learning - is also implemented in online courses [10,21], whereas the education medium becomes partially or completely virtual (depending on the chosen training model - mixed or completely remote). The course design commences when one is able to understand the capabilities and limitations of the online format. In addition, an open online course is built around the instructor, as well as their requirements and demands. Research results confirm that the charisma of the teacher, their passion and energy are the determining factors for students of online courses in assessing the quality of video lectures. The course is created for students, and it is their goals and objectives that are put at the forefront of the designing. But the key element of this course is its authors, the bearers of the "living" and "practical" knowledge and expertise [20]. The online format implies that this knowledge can be partially conveyed to a much larger audience than traditional offline methods. It is significant not only to provide the detailed explanation of the material, but also to supplement it with some assessment and evaluation. Otherwise, the audience may find problems with the readiness for theoretical and practical work.

The strengths and advantages of online learning include the following:

- the coverage of a large number of students-mass participation;

- the use of modern and interactive technologies to present theoretical material and complete tasks;

- mobility and training $24 / 7$ - the ability to study anywhere and anytime;

- variability and diversity;

- "repeated study" (interesting or complicated materials can be accessed multiple times for clarification);

- professional development through online courses for people with special needs (inclusive education);

- opportunity for self-development and self-discipline while studying flexible hours;

- the optimization of the learning process (students' autonomous work, reducing the teacher's contact);

high-quality organization of classroom and students independent work, which is not always consistently and validly assessed during full-time training;

- increase of the University rating, its popularity and overall students' motivation.

One could add that in the online course, students are exposed to less stress when completing evaluation tasks, as they are placed in a more comfortable environment (home or any convenient place), and also promptly obtain final results and mistakes correction. "Working outside class encourages students to study independently using the E-learning interactive activities and thus spend more time engaged and immersed in the English language which improves their language proficiency" concludes in his research [1]. On the other hand, it is more difficult for the teacher to control and properly assess how independently this work is performed [18]. Therefore, one has to create tasks that can be completed not just by copying the data from the lecture materials, but only by means of thorough comprehension of the topic.

The modern generation exists within the framework of a virtual and digital environment; consequently, online courses are a combination of students' free time with their studies to provide them with an opportunity to learn in an interesting and relevant manner. In the discussion of the subject, author of work [16] clarifies the following, "Online learning contains video lectures, quizzes, unit tests, and supplementary resources. In addition, the online course platform also has a discussion forum between teaching staff and students for answering questions. Offline classroom teaching is an extension and expansion of online courses. Therefore, teachers should use a mixed teaching mode that combines online and offline teaching activities. It is totally different from the traditional classroom teaching mode". Taking online courses may provide additional career guidance to future applicants, 
information support to undergraduates and postgraduates who studied in a different field of study at the previous stage of education. At the same time, online training provides ample opportunities for the implementation of joint activities of all participants in the educational process.

In addition to the advantages listed above, the following can be noted: online courses also assist in teaching international students when it is difficult for them to learn in the general students' flow, and the teacher should pay additional attention to their demands. Online courses are also important to optimize teaching time (as well as release from the so-called "voice" load), either for academic activity or to improve the quality of educational and methodological work. The listed advantages of online learning could be supplemented by the fact that it motivates instructors to master new educational technologies. $\mathrm{H} . \mathrm{Pu}[25]$ emphasizes that "these unique times offer opportunities for ELT instructors who have grown used to face-to-face settings to take a closer look at online teaching with fresh eyes and revitalize their teaching repertoire".

In general, the strengths of online courses facilitate self-expression, transferring teaching experience and expertise to an unlimited number of students; the accessibility of education for the students, the opportunity to improve their skills, and acquire new contacts for cooperation in the future.

The weaknesses and vulnerabilities of online learning in foreign languages include:

- large time-consuming and high cost of design of online courses (from 500 thousand to 1 million rubles, the cost of support and follow-up work might reach up to 200 thousand rubles per year);

- loss of students' ability to analyze and synthesize, since the online courses material is provided in ready-made shape and give less opportunities for discovery and both creative and critical thinking;

- the ability to perform multiple tests (as a result, the assessment may not adequately reflect the student's knowledge);

- problems with proctoring (students' authentication) hence the inability to control the real progress, because tasks might be fulfilled by someone more competent;

- the excessive formalization and regulation of training, restrictions and limitations (and in some cases suppression) of its creative component;

- "one-sided" presentation of educational material by the lecturer, limitations of "live" dialogue that can distract the audience's attention of listeners. This limits questions, remarks, supplement materials and illustrations that "enliven" the educational material and motivate audiences to keep close attention to the presented data. The lack of direct (personal) interaction between the instructor and the student (trainee) does not allow to fully implement the competence approach, focusing more on obtaining knowledge, and less on the formation of skills.

However, the lack of a direct contact with the teacher can be considered as a positive point, if he/she does not possess high qualification. For example, an eminent professor's lectures attract a larger audience than an ordinary teacher's class. Teaching staff are usually competent in their narrow subject matter, and they need significant support from specialists in modern pedagogical technologies, since a course is to fit and meet the requirements of the structure of the Bologna system.

Despite the above-mentioned shortcomings, positive results may be achieved taking into account the specifics of the field of study and a rational approach to the development and use of an online course with a specific goal. According to Sh. Kong [16], "the online open course has transformed our teaching concepts enormously. First of all, it makes learning process more participatory, exploratory and experiential, which naturally changes the roles of teachers and students. For students, the online learning can be done anywhere and the learning styles are quite flexible. However, they should learn and complete assignments more independently, and knowledge internalization is fulfilled mainly by themselves". The researcher also emphasizes that "on the other hand, the role of teachers is to guide, inspire and supervise students' learning process. This puts forward higher requirements on teachers' teaching ability and information quality".

It should be emphasized that so far, no massive open online course can compare with a teacher's work at the initial stage, when a conceptual apparatus based on logical thinking is created. Not every student is able to independently organize their time, workspace, and take a disciplined approach to completing tasks. Schedules, colloquiums, and the opportunity to compare their knowledge with the knowledge of other students play motivational and organizing roles. Online learning is more focused on keen students; it does not have enough tools to control the availability of conscious knowledge and skills.

Some subjects, including a foreign language, require the formation of oral speech skills (especially spontaneous abilities) through face-to-face communication with the teacher and other students, so in this case, an online course can only be a useful addition to classroom work. As pointed out in [34] "Due to the ready availability of new technologies, opportunities for the incidental as well as deliberate practice of English have multiplied and far exceed what can be done in more formal environments". However, in this area, online learning opportunities are limited, especially in the format of mass online courses [7, 22]. Both at the initial stage and at the subsequent (intermediate and advanced) stages, "live" communication and constant interaction with the instructor should play the leading role while achieving success in the correct mastery of language material and the development of 
communicative competence.

Each stage of learning a foreign language must be saturated with speech exercises, which are the decisive factor for practical mastery of a foreign language (for example, see $[28,29])$. It is necessary that the students made oral presentations, participated in discussions and talked with each other in a foreign language. It should be noted that the measure of students' knowledge, skills and abilities cannot be assessed only by passing of a test (which is one of the training exercises). The key assignments include: asking questions and answering them in a conversation with a teacher or in a pair of "student - student"; determining the main topic of the proposed material, abstracts, etc. This is especially true if the student studies a foreign language for further use in oral and written communication in the professional sphere, as well as for education abroad [20]. Moreover, the most vulnerable aspects of speech communication that are extremely difficult to work on in an online format are: phonetics, writing, and speaking, as they all need discussion, feedback, and constant control.

At the same time, it should be noted that the formation and automation of certain skills in the use of certain grammar units, the development of reading and listening skills can be implemented in an online format [22]. N.G. Mathew et al. [19] observe that, "most of the research studies in technology-mediated language instruction focused on the effectiveness of technological aids in second/foreign language classrooms". They also state the following: "The use of computers as instructional aids facilitates language input because of their ability to integrate multimedia material such as videos, images, and text simultaneously into one single screen". Since such courses and technologies already exist, it is necessary to train the teaching staff to use these materials and involve them in further optimization, as well as the development of new materials in this area.

In our opinion, there are still more weaknesses in online learning than strengths. Theoretically it is still possible to give the audience information, but practically it is problematic. In addition, it is not possible to fully implement knowledge assessment. Passing the test does not mean that students have learned the material correctly (one can pass the test basing on logic, not knowledge). The threats of online learning can be attributed to the reduction in the number of teachers who are not fully competent in computer technology, but their discipline is taught at a high professional level according to the traditional system. Personal communication between the instructor and the student, in addition to the information component, also contains the aspect of mentoring. This concept is currently in great demand and commonly lacking. Online training is appropriate in the case of deeply motivated students. But in practice, one can often face the inability to effectively search for the necessary information and plan their own time. In addition, virtual reality has limitations in teamwork, which is essential in real life.

Widely known is the statement of the Russian psychologist V.P. Zinchenko that a teacher is a subject, a bearer of not only institutionalized, but also "living" knowledge, without whom complete education is impossible (for more information, see [36]). Indeed, the task of the teacher is not just broadcasting and conveying information. He/she is the creator of the educational environment and paradigm, outside of which education is defective. Undoubtedly, the advantages of online learning are obvious. However, it is necessary to calculate all the risks and stop the pursuit of rash implementation of not fully tested innovations. Online learning, like any tool, depends on an expert who uses it. It will be practically useful if the online education system is perceived as a supplement to the traditional system, as an effort to compensate for its most vulnerable points.

Summing up, it should be noted that online courses for teachers are a valuable source of methodological experience, which is generally positive. This experience is especially useful if they are planning to create their own online course. However, there are many disciplines in which online courses cannot replace "live" communication with the teacher. In modern conditions, online training is relevant and necessary, but only as a supplement to the traditional teaching.

Thus, the analysis of the problem of implementing online learning in the educational process revealed its strengths and weaknesses. It is shown that the potential of online courses is to provide users with broad opportunities to develop skills in innovative types of research, self-education, and intellectual activities. Along with traditional training, they can ensure the formation of an intellectually and professionally developed personality, promote the development of independent work, and provide access to new sources of educational information. The didactic potential of online courses provides opportunities for the formation of new forms of independent cognitive activity and contributes to the effective use of Internet resources in the educational process.

\section{Discussion}

The Internet provides and offers innovative opportunities for better mastering of a foreign language through digital communication, which is subdivided into synchronous (Chats and messengers) and asynchronous (E-mail, forums) types. As shown in practice, synchronous kind is more effective for individual mastering of language skills at a sufficiently high level. While asynchronous communication assists thorough pairing and group work, as opposed to spontaneous communication. In the work [23] define both types of 
digital communication (within the framework of e-learning) as "exchanging scanned printed materials, graphs, business documents, photographs, charts, newspapers and magazines using electronic transmission methods and processing information". Due to its availability and accessibility, there is an observed increase in frequency of integration of electronic communication into the educational process, which allows authenticating communication; expands the circle of communication on the relevant issues; extends knowledge about the culture of the target language; increases motivation and encourages students to master the linguistic skills through specific teaching methodologies. Digital communication is capable of transferring not only the required data but basic emotions. For instance, the rules of communication are supplemented by the so-called "emoticons" ("smiles"), special symbols for conveying emotions and intonation of the author of messages. According to [15], these rules are available for study at the following addresses: The Smileys and Acronyms Dictionary (www.seekwellness.com); The Net: User Guidelines and Netiquette (www.fau.edu); A Beginner's Guide to Effective Email (www.webfoot.com).

The final assessment of students' performance is determined by their participation in correspondence, and the role of the teacher is to organize the exchange of information and assess the completed assignments. For instance, the following resources may be used for creating joint projects and ensuring communication with pen pals in a foreign language: Intercultural Classroom Companies (http://www.iecc.org); EPALS Classroom Exchange (www.epals.com); The Rap Pal Exchange (www.iwaynet.net); Thomas Robb's E-Mail Keurals for Language Fluency (http://www.kyoto-su.ac.jp); E-pal classroom code (http://www.epals.com).

The method of e-mail projects is used on condition of proper planning, interest in the topic, motivation of students, and an appropriate level of the group proficiency. Communication is carried out in a foreign language with real partners, topical problems are discussed, and the language competence of students is expanded. Practice shows that the work on any project consists of several stages: 1) organizational: search and presentation of partners (discussion of information); 2) selection and formulation of the issue points (definition of goals and objectives, discussion of the plan of activities); 3 ) analysis of methodological techniques and organization of students' work (structuring, allocation of stages, distribution into groups according to interests, determination of planned results); 4) work on the project (development of tasks for groups, consultations, exchange of information, obtaining results); 5) presentation of the project and summing up. An Internet project must meet such requirements as: the presence of a research problem, the practical significance of the results, the structuring of activities, the distribution of roles to the project participants, the use of research methods in the project. As a result, the listed forms of students' provide advantages for the teacher as an opportunity to move from standard to creative activities; using a flexible system for assessing students' knowledge, including self-control and self-assessment; opportunities to share experience and improve work efficiency.

One of the most successful digital tools is the e-book (or digital course books). According to [6] "the type of organization and the method of delivery to the student determines the division of multimedia textbooks into the following types: CD-ROM with or without a printed copy; specially designed Internet sites; applications for mobile devices". In modern higher education, electronic textbooks are usually available online through the distance learning system, which is an open access to all students. From our point of view, in order to match a given curriculum with teaching aids, instructors and professors should act as authors of various digital resources. Such resources may contain educational materials, as well as an audio / video course, provided by native speakers; tests, posters, teaching aids and additional materials. Programs and electronic textbooks consolidate the skills of determining lexical meanings and grammatical structures; they form writing skills and associate visual images with mental pictures while mastering foreign language material. The advantages of electronic course books are the following: accessibility, increasing motivation due to the visual presentation of the material (illustration, sound, video, animation); interactivity as an opportunity to increase the speed of mastery of the educational material; the feedback in the form of tests, designed for quick control; the ability to adjust and edit the electronic course book as new data becomes available; the increase of motivation and elimination of student overload. The disadvantages of e-books can be explained by the limitation of the possibilities of group work, the lack of real communication; as a result, e-books are often assigned an auxiliary or supplementary role in training.

Telecommunication provides more possibilities for solving communication problems using the Internet in on-line mode. Such classes are used for experimental, distance and variable learning, as well as an addition to extracurricular work (academic communities, elective courses, clubs in foreign languages). The use of telecommunication means in an educational context in teaching foreign languages is manifested in the exchange of messages - often in the process of a telecommunications project a certain topic is studied with a discussion of the results through correspondence, as well as communication in real time. Telecommunication is also expressed in e-learning and can serve as a simulator for teachers and students in the study of special topics, establishing contacts with world experts in various fields of knowledge, varying from the development of educational projects to the structure of the educational 
process in an interactive mode. In the modern world, electronic communication takes place during the simultaneous completion of tasks of competitions and projects of different levels. Students are remotely offered the same tasks. Data exchange takes place in the form of a group question-answer game, drawing up conceptual charts, using modern technologies (cluster, insert, etc.) to develop critical thinking in the purpose of further socialization as stipulated by the Russian Federal State Educational Standards.

Educational telecommunication projects are based on topical data exchange: collection, processing, comparison, analysis of the information on a given issue. Students are both creators and consumers of information in the exchange process. The ability to use information extracted from almost any major library in the world, archives of international scientific organizations (NASA, UNESCO, etc.) is an indisputable advantage of Internet tools. On-line modeling of the activities of participants in telecommunication projects is focused on the development of interaction principles; it is based on telecommunication support of traditional forms of education in combination with modern tools.

The web-quest technology provides for independent search work on the Internet using a list of websites that correspond to the subject of the project and the level of knowledge of the students. The Internet resources that contain interactive materials on a foreign language include:

- Letter Generator (www.readwritethink.org); a website for developing listening skills (www.english-test.net/toeic/listening/the_bund_shan ghai.html). It features a large collection of audio files for listening to foreign language speech;

- memorizing idioms and phrasal verbs of the English language (http://usefulenglish.ru/idioms). It contains examples of usage of words and phrases, idioms and fixed expressions in various situations in oral and written speech;

- $\quad$ site for learning English (www.native-english.ru); the comprehensive grammar reference, tests, idioms and proverbs, songs, poems, etc.;

- BBC Russian-Learning English. The portal offers tests, videos with radio reports from $\mathrm{BBC}$ correspondents; BBC World Service provides an opportunity to read and listen to news in different languages;

The other resources include: English.ru which offers to determine the level of proficiency in English; "America homepage" introduces states, cities, history, culture of the USA; abc-english-grammar.com features the study of grammar, phonetics and radio programs; lingualeo.ru is designed to improve the skills of listening comprehension, reading, correct pronunciation, and expanding vocabulary; alleng.ru teaches phonetics and includes grammar material, English vocabulary, slang, idioms, dictionaries, tests, essays, abstracts, audiobooks, lyrics, scripts, etc.

To increase the motivation of learning, it is advisable to integrate Internet resources into the educational process, since they are characterized by multimedia and contain various types of information (text, sound, graphic, animation, video) providing a high degree of visibility, as well as instant feedback. According to [24], "in the conditions of modern society, the information and communication competence of a teacher, that is, their ability to solve professional pedagogical problems with the involvement of information and communication technologies, is becoming a vital component of professionalism". A.V. Lebedev et al [17] point out "the importance of thorough students' needs analysis prior to starting a course; the possible scenarios for significant adaptation of course contents due to constant changes in national educational standards and curricula hours; the highly responsible role of an English for specific purposes teacher, a professional, performing multiple assignments".

\section{Conclusions}

Based on the results of the study, the following conclusions are made:

- the use of Internet technologies is characterized by the implementation of a structural approach that provides a productive combination of various information resources in novel ways, the development of students' creative abilities and problem-solving skills;

- the purpose of e-learning is to acquire new knowledge in the process of active communication to solve educational problems, which include the formation of communication skills; mastering linguo-cultural knowledge, developing skills with the aim of using them in real situations; revealing the creative potential of students;

- Internet technologies are the basis for a new methodological paradigm in language teaching. They facilitate the resolution of the task to support the educational work of students; provide real communication with native speakers; universal access to the educational process through the data of centralized information systems;

- the online and multimedia facilities do not and cannot substitute instructor's work as a mentor or a guide, such tools should be implemented validly, combining digital and traditional teaching aids. As a result, the use of new information technologies makes it possible to increase the efficiency of teaching, improve the skills of everyday and professional communication in a foreign language, and develop the communicative, cognitive, and creative abilities in students. 


\section{REFERENCES}

[1] A.E. AlAdl. Investigating Students' Attitude towards (LEP) E-Learning Model for Learning English in Delta University. International Journal of English Language Teaching (IJELT), Vol. 6, No. 7, 31-42, September 2018.

[2] Z. Bárkányi, S. Melchor-Couto. Foreign Language Anxiety on a Massive Open Online Language Course, 2017, Online available from https://doi.org/10.14705/rpnet.2017.eurocall2017.683 (accessed 30.09.2020).

[3] N.E. Bobrova, A.V. Lebedev, I.S. Pinkovetskaia. Peculiarities of the English Legal Text Discourse: The Issues of Interpretation and Translatability. Journal of History Culture and Art Research, Vol. 9(2), 318-328, 2020. Online available from http://dx.doi.org/10.7596/taksad.v9i2.2689 (accessed 01.10.2020).

[4] C.A. Chapelle. Computer-Assisted Teaching and Testing. In Handbook of Technology, Second Language Teaching and Learning. New York and London: Blackwell-Wiley, 2017.

[5] H. Chiang. Comparison between Teacher-Led and Online Text-to-Speech Dictation for Students' Vocabulary Performance. English Language Teaching, Vol. 12, No. 3, 77-93, 2019. Online available from https://doi.org/10.5539/elt.v12n3p77 (accessed 30.09.2020).

[6] N.Yu. Duseva, S.V. Petryakova. The Typification of Multimedia Technologies in Teaching, Contemporary Issues of Science and Education. Vol. 4, 2016. Online available from

http://www.science-education.ru/ru/article/view?id=25026 (accessed 12.05.2018).

[7] G.R. Eremeeva, O.K. Melnikova. English through the Moodle System. Kazan Pedagogical Journal. Kazan: Publishing House "The Institute of Pedagogy, Psychology and Social Problems", Vol. 1 (126), 103-107, 2018.

[8] V.P. Furmanova. The Paradigm of Intercultural Communication and the Methodology of Teaching Foreign Languages. Intercultural Communication language - culture - personality. Saransk, N. P. Ogarev's Mordovia State University, 6-9, 2003.

[9] R. Godwin-Jones. Riding the Digital Wilds: Learner Autonomy and Informal Language Learning. Language Learning \& Technology, 8-25, Vol. 23(1). Online available from https://doi.org/10125/44667 (accessed 30.09.2020).

[10] N.P. Goncharuk, E.I. Khromova. Integration of Pedagogical and Information Technologies in the Educational Process. Kazan Pedagogical Journal. Kazan: Publishing House "The Institute of Pedagogy, Psychology and Social Problems", Vol. 4 (129), 32-37, 2018.

[11] A. Hanifi. Electronic Evaluation: Facts, Challenges and Expectations. International Journal of English Language Teaching (IJELT), Vol. 7, No. 4, 1-5, June 2019.

[12] L. Jiang, Sh. Yu, Yi Zhao. An EFL Teacher's Investment in Digital Multimodal Composing. ELT Journal, Vol. 74, No. 3, 297-306, July 2020. Online available from https://doi.org/10.1093/elt/ccaa010 (accessed 30.09.2020).

[13] L. Khubyari, M.H. Narafshan. A Study on the Impact of Mall (Mobile Assisted Language Learning) on EFL Learners'
Reading Comprehension. International Journal of English Language Teaching (IJELT), Vol. 6, No. 9, 34-44, December 2018

[14] N.S. Kirgintseva, S.A. Nechayev. Modern Trends in the Development of Educational Tools Based on IT Techniques. Information Technology and Education, Vol. 3, 79-82, 2013.

[15] N.A. Kocheturova. Methodology of Teaching Foreign-Language Electronic Communications Based on Telecommunication Projects in a Non-Linguistic Institution: Abstract of the Dissertation: 13.00.02. Moscow, 2009.

[16] Sh. Kong. Practice of College English Teaching Reform Based on Online Open Course English Language Teaching, Vol. 12, No. 5, 156-16, 2019. Online available from https://doi.org/10.5539/elt.v12n5p156 (accessed 30.09.2020 ).

[17] A.V. Lebedev, I.S. Pinkovetskaia, M.A. Rozhkov, L.V. Tsybina. Implementation and Peculiarities of English for Specific Purposes Course Design at Ogarev's Mordovia State University. Universal Journal of Educational Research, Vol. 8, No. 1, 2020, 178-182. DOI: 10.13189/ujer.2020.080122.

[18] S.V. Manukyants. The Organization of Students' Independent Work at an Electronic Course on Basic Economic Disciplines. Modern Problems of Theoretical Education. Materials of the All-Russian Scientific and Methodological conference. Yoshkar-Ola: Volga State Technical University Publishing House, 60-63, 2015.

[19] N.G. Mathew, P. Sreehari, A.M. Al-Rubaat. Challenges and Implications of Virtual E-Learning Platform in EFL Context: Perceptions of Teachers. International Journal of English Language Teaching (IJELT), Vol. 7, No. 2, March, 100-116, 2019.

[20] M.I. Murneva, N.A. Shestakova, E.V. Samoilova. Modern Technology of Teaching English at Non-Linguistic Faculties: Science or Art? Philological Science. Issues of Theory and Practice. Tambov, No. 3-2 (81), 415-418, 2018.

[21] I.N. Nekhaev. The Analysis of the Learning Process Quality Using Online Courses. Best Practices of E-Learning. Materials of the II-d Methodological Conference. Ministry of Science and Education of the Russian Federation; Tomsk State University, 8-14. 2016.

[22] N.S. Nurieva, T.D. Borisova. The Use of Online Video Materials in Students' Foreign Language and Professional Training. Kazan Pedagogical Journal. Kazan: Publishing House "The Institute of Pedagogy, Psychology and Social Problems", No. 4 (129), 158-163, 2018.

[23] E.S. Polat, M.Yu. Bukharkina, M.V. Moiseeva, A.E. Petrov. New Pedagogical and Information Technologies in the Education System: Textbook for Students of Pedagogical Universities and Higher Education Institutions. Ed. E. S. Polat. M.: Akademiya. 2005.

[24] I.N. Polynskaya. Information and Communication Technologies in Artistic and Pedagogical Education. Fundamental Research, Vol. 2-14, 3170-3174, 2015.

[25] H. Pu. Implementing Online ELT in the Time of Crisis: Ordeal or Opportunity? ELT Journal, Vol. 74, No. 3, 345348 , July 2020. Online available from https://doi.org/10.10 93/elt/ccaa030 (accessed 30.09.2020) 
[26] T.M. Roose, G.E. Newell. Exploring Online Discussions through an Academic Literacies Approach. ELT Journal, Vol. 74, No. 3, 258-267, July 2020. Online available from https://doi.org/10.1093/elt/ccaa027 (accessed 30.09.2020)

[27] S. Kh. Shahzad, J. Hussain, N. Sadaf, S. Sarwat, U. Ghani, R. Saleem. Impact of Virtual Teaching on ESL Learners' Attitudes under Covid-19 Circumstances at Post Graduate Level in Pakistan. English Language Teaching, Vol. 13, No. 9, 1-9, 2020. Online available from https://doi.org/10.5539/ elt.v13n9p1 (accessed 30.09.2020)

[28] N.V. Shamina. Innovative Technologies of Teaching Foreign Languages at Non-Linguistic Faculties. Bulletin of the Mordovia University: Humanities. N.P. Ogarev's Mordovia State University. Saransk, No. 3, 218-221, 2008.

[29] N.V. Shamina. From the Experience of Developing Students' Listening, Speaking and Critical Thinking. Linguistic and Extra-Linguistic Problems of Communication: Theoretical and Applied Aspects. Interuniversity Collection of Scientific Papers. Saransk: Mordovia N. P. Ogarev State University Publishing House, Vol. 11, 248-252, 2017.

[30] N.V. Shamina. Online Learning in the Educational Process: Strength and Weaknesses. Kazan Pedagogical Journal. Kazan: Publishing House "The Institute of Pedagogy, Psychology and Social Problems”, No. 2 (133), 20-24, 2019.
[31] A.V. Soboleva. The Use of Multimedia Technologies in Teaching Foreign Languages. Pedagogy: traditions and innovations: materials of the IV International Academic Conference (Chelyabinsk, December 2013). Chelyabinsk, Two Komsomolets, 119-123, 2013.Online available from https://moluch.ru/conf/ped/archive/98/4582/ (accessed 12.05.2018).

[32] H. Tawil. Enhancing Language Learning Through Technology. International Journal of English Language Teaching (IJELT), Vol. 7, No. 2, 1-18, March 2019.

[33] S.V. Titova. Internet Resources and Services in Teaching Foreign Languages. Moscow, Moscow University Publishing, 2009.

[34] R. Trinder. Informal and Deliberate Learning with New Technologies. ELT Journal, Vol. 71, No. 4, 401-412, October 2017.

[35] W. Tseng, H. Cheng, T. Hsiao. Validating a Motivational Process Model for Mobile-Assisted Language Learning. English Teaching \& Learning, Vol. 43, No. 4, 369-388, December 2019. Online available fromhttps://doi.org/10.10 07/s42321-019-00034-1 (accessed 30.09.2020)

[36] V.P. Zinchenko. Living Knowledge. Samara: Samara State Pedagogical University Publishing House, 1998. 